\begin{tabular}{|c|l|}
\hline Title & Dicarboxylic acids, ketocarboxy lic acids and dicarbony Is in the urban roadside area of Hong Kong \\
\hline Author(s) & Ho, K.F.; Lee, S.C.; Cao, J.J.; Kawamura, Kimitaka; W atanabe, Tomomi; Cheng, Y.; Chow, Judith C. \\
\hline Citation & $\begin{array}{l}\text { Atmospheric Environment, 40(17), 3030-3040 } \\
\text { https://doi.org/10.1016/.atmosenv.2005.11.069 }\end{array}$ \\
\hline Issue Date & 2006-06 \\
\hline Doc URL & http://hdl.handle.net/2115/26147 \\
\hline Type & article (author version) \\
\hline File Information & AE40-17.pdf \\
\hline
\end{tabular}

Instructions for use 


\title{
Dicarboxylic acids, ketocarboxylic acids and dicarbonyls in the urban roadside area of Hong Kong
}

\author{
K. F. Ho ${ }^{a}$, S. C. Lee ${ }^{a}$, J. J. Cao ${ }^{b}$, K. Kawamura ${ }^{c}$,Tomomi Watanabe ${ }^{c}$,Y. \\ Cheng $^{\text {a }}$, Judith C. Chow \\ ${ }^{a}$ Research Center of Urban Environmental Technology and Management, Department \\ of Civil and Structural Engineering, The Hong Kong Polytechnic University, \\ Hun Hom, Kowloon, Hong Kong \\ ${ }^{\mathrm{b}}$ SKLLQG, Institute of Earth Environment \\ Chinese Academy of Sciences, China \\ ${ }^{c}$ Institute of Low Temperature Science \\ Hokkaido University, Sapporo, Japan \\ ${ }^{\mathrm{d}}$ Division of Atmospheric Sciences, \\ Desert Research Institute, 2215 Raggio \\ Parkway, P.O. Box 60220, Reno, NV 89506, U.S.A
}

\begin{abstract}
Homologous dicarboxylic acids $\left(\mathrm{C}_{2}-\mathrm{C}_{12}\right)$, ketocarboxylic acids $\left(\omega \mathrm{C}_{2}-\omega \mathrm{C}_{9}\right.$, pyruvic acid) and dicarbonyls (glyoxal and methylglyoxal) have been studied in the urban aerosol samples $\left(\mathrm{PM}_{2.5}\right)$ collected from the Hong Kong roadside atmosphere during winter and summer of 2003 using a capillary GC and GC-MS method. The concentrations of total dicarboxylic acids, ketocarboxylic acids, and $\alpha$-dicarbonyls were higher in winter than in summer (except for some species like phthalic acid, $\mathrm{Ph}$ ). Oxalic $\left(\mathrm{C}_{2}\right)$ acid was found as the most abundant species in summer, followed by $\mathrm{Ph}$. Oxalic $\left(\mathrm{C}_{2}\right)$ acid was also found as the most abundant species in winter, but followed by malonic $\left(\mathrm{C}_{3}\right)$ acid. The $\mathrm{C}_{2}$ diacid comprised 28-66\% of the total diacid concentrations. The diacids with higher carbon numbers were less abundant, although $\mathrm{C}_{9}$ diacid was relatively abundant $(2 \%)$. Glyoxylic acid $\left(\omega \mathrm{C}_{2}\right)$ and methylglyoxal were found as the most abundant ketocarboxylic acid and dicarbonyl in both seasons,
\end{abstract}

\footnotetext{
${ }^{*}$ Corresponding author. Tel.: +86-852-27666011; fax: +86-852-23346389.

E-mail address: ceslee@polyu.edu.hk (S.C. Lee).
} 
respectively. The concentrations of the total diacids, total ketoacids and total dicarbonyls ranged from 224 to $1381 \mathrm{ng} \mathrm{m}^{-3}, 10$ to $89 \mathrm{ng} \mathrm{m}^{-3}$ and 5 to $21 \mathrm{ng} \mathrm{m}^{-3}$, respectively. Their relative abundances in $\mathrm{PM}_{2.5}$ mass were $1.18 \%, 0.06 \%$ and 0.02 $\%$, respectively. High concentrations of toluene (winter: $33.8 \mu \mathrm{g} \mathrm{m}^{-3}$; summer: 41.3 $\mu \mathrm{g} \mathrm{m}^{-3}$ ) and naphthalenes (winter: $1.2 \mu \mathrm{g} \mathrm{m}^{-3}$; summer: $1.9 \mu \mathrm{g} \mathrm{m}^{-3}$ ) observed were one possible source for the abundant phthalic and also methylmaleic acids detected.

Keywords: dicarboxylic acids, ketocarboxylic acids, dicarbonyls, seasonal variations, Hong Kong

\section{Introduction}

Dicarboxylic acids are an important group of water-soluble organic compounds (WSOC) in the atmospheric aerosols (Grosjean et al., 1978; Kawamura and Ikushima, 1993; Rogge et al., 1993; Jacobson et al., 2000; Kawamura and Yasui, 2005). They have received much attention because of their potential roles in affecting the global climate. Because of the low vapor pressures and high water solubility, diacids have an influence on the chemical and physical properties of aerosols (Lightstone et al., 2000). Consequently, they may have direct and indirect effects on the earth's radiation balance by scattering incoming solar radiation, which counteracts the global warming caused by the increase of greenhouse gases.

Among these dicarboxylic acids, oxalate is generally the most abundant, followed by malonate and succinate in atmospheric aerosols (Kawamura and Ikushima, 1993; Kawamura et al., 1996a; Kerminen et al., 2000). Total diacids account for about $1-3 \%$ of the total particulate carbon in the urban areas and even above $10 \%$ in the remote marine environment (Kawamura and Ikushima, 1993; 
Kawamura et al., 1996b, c; Sempéré and Kawamura, 1996; Kawamura and Sakaguchi, 1999; Kerminen et al., 2000). Oxidative degradation of anthropogenic or biogenic volatile organic compounds by tropospheric oxidants and/or primary traffic emissions have been proposed as the origins of dicarboxylic acids (Kawamura and Kaplan, 1987; Kawamura et al., 1996a; Warneck, P., 2003). Owing to high water solubility, the WSOC, especially diacids, have a potential to modify the surface tension and hygroscopic properties of atmospheric particles including particle size and cloud condensation nuclei activity (Shulman et al., 1996; Cruz and Pandis, 1998; Jacobson et al., 2000). Dicarboxylic acids in total suspended particulates (TSP) and $\mathrm{PM}_{10}$ have been extensively measured in urban (Kawamura and Ikushima, 1993; Kawamura et al., 1996c; Khwaja, 1995; Kerminen et al., 2000; Yao et al., 2002; Fraser et al., 2002; Li and Yu, 2005), continental background (Limbeck and Puxbaum, 1999; Falkovich et al., 2005), and remote atmosphere (Kawamura and Usukura, 1993; Kawamura and Sakaguchi, 1999; Kawamura et al., 1996a, b; Kerminen et al., 1999).

So far, most studies on low molecular weight dicarboxylic acids and their salts have focused on their chemical characterization and their formation in TSP (Kawamura and Kaplan, 1987; Kawamura et al., 1996a; Limbeck et al., 2001; Rohrl and Lammel, 2001; Li and Yu, 2005). However, only limited data of the diacids in $\mathrm{PM}_{2.5}$ have been reported (Meszaros et al., 1999; Wang et al., 2002; Yao et al., 2004; Yue and Fraser, 2004; Huang et al., 2005). The concentration ratios of these diacids, in particular the $\mathrm{C}_{3} / \mathrm{C}_{4}$ and $\mathrm{C}_{6} / \mathrm{C}_{9}$ mass ratio, are useful to understand the production of dicarboxylic acids and the source strength of anthropogenic and biogenic precursors in the atmosphere, respectively. The $\mathrm{C}_{3} / \mathrm{C}_{4}$ ratio has been reported to be 0.25-0.44 from vehicular emissions (Kawamura and Kaplan, 1987). On the other hand, the mass ratio of $\mathrm{C}_{3} / \mathrm{C}_{4}$ of secondary aerosol is much larger than unity in remote 
aerosols (Kawamura et al., 1996a; Kawamura and Sakaguchi, 1999). Other than primary vehicular emissions and secondary sources, biogenic contributions of dicarboxylic acids are common, especially in rural areas. As azelaic acid $\left(\mathrm{C}_{9}\right)$ has been proposed as one of the reaction products by ozonolysis of biogenic unsaturated fatty acids (Kawamura and Kaplan, 1983; Yokouchi and Ambe, 1986; Kawamura and Gagosian, 1987; Stephanou and Stratigakis, 1993) and adipic acid $\left(\mathrm{C}_{6}\right)$ has been proposed as one of the products by oxidation of anthropogenic cyclohexene (Grosjean et al., 1978; Hatakeyama et al., 1987; Kawamura and Ikushima, 1993), the $\mathrm{C}_{6} / \mathrm{C}_{9}$ ratio can be used as a potential indicator to show the strength of biogenic sources.

In this paper, $\mathrm{PM}_{2.5}$ samples from the roadside atmosphere of Hong Kong were collected during summer and winter of 2003. The molecular composition of low molecular weight (LMW) diacids $\left(\mathrm{C}_{2}-\mathrm{C}_{12}\right)$, ketoacids $\left(\omega \mathrm{C}_{2}-\omega \mathrm{C}_{9}\right.$, pyruvic acid) and $\alpha-$ dicarbonyls $\left(\mathrm{C}_{2}-\mathrm{C}_{3}\right)$ employing $\mathrm{BF}_{3} / \mathrm{n}$-butanol derivatization followed by $\mathrm{GC}$ and GC/MS were for the first time determined in the urban roadside area of Hong Kong. The samples were also analyzed for organic carbon (OC). Here, we reported the seasonal variations of bi-functional organic acids and carbonyls in the urban atmosphere. The relative contributions of diacids in $\mathrm{PM}_{2.5}$, organic carbon (OC) and TC during winter and summer were also examined. The impact of ozone and solar radiation on the concentrations and the composition of these dicarboxylic acids are then discussed.

\section{Samples and Methods}

Hong Kong is located along the coast of the South China Sea which is connected to the Pearl River Delta Region in China. High ambient suspended particulate loading has been a persistent problem in Pearl River Delta Region (PRDR). 
Hong Kong is a warm, humid and cloudy coastal city. According to the Hong Kong Observatory, the annual average temperature and relative humidity was $23^{\circ} \mathrm{C}$ (range from 14 to $32^{\circ} \mathrm{C}$ ) and $77 \%$ (range from 65 to $83 \%$ ), respectively, in 2003 . Vehicular emissions are the major primary local air pollutants in Hong Kong. High concentrations of $\mathrm{PM}_{10}$ usually are observed in the winter because of the frequent development of stagnating high pressure systems and inversion layers in the lower atmosphere and less chance of precipitation in winter (Environmental Protection Department, 2002).

Samples of $\mathrm{PM}_{2.5}(\mathrm{n}=14)$ were collected at the roadside environment at the Hong Kong Polytechnic University during January, June and November 2003 using mini volume (mini-vol.) samplers (Airmetrics, USA), operated at flow rates of $51 \mathrm{~min}^{-1}$. The site was situated at about $\sim 1.5 \mathrm{~m}$ above ground level in The Hong Kong Polytechnic University, and about $1 \mathrm{~m}$ away from the main traffic road that leads to the Cross Harbor Tunnel. The traffic volume on this road is extremely high with about 170,000 vehicles per day. $\mathrm{PM}_{2.5}$ impactor was installed on top of the preseparator assemblies to collect $24 \mathrm{~h}$ PM samples. Samples were collected on precombusted $\left(800^{\circ} \mathrm{C}\right.$ for $\left.3 \mathrm{~h}\right) 47 \mathrm{~mm}$ Whatman quartz microfibre filters $(\mathrm{QM} / \mathrm{A})$. The exposed filters were stored at $-4{ }^{\circ} \mathrm{C}$ prior to analysis to prevent the evaporation of volatile components. The $\mathrm{PM}_{2.5}$ masses were determined gravimetrically using an electronic microbalance with $1 \mu \mathrm{g}$ sensitivity (ME5 Microbalance, Sartorius). Also, field blank filters were collected to subtract the artifacts due to adsorption of gasphase organic components onto the quartz filter during and/or after sampling.

Filter samples were analyzed for water-soluble dicarboxylic acids, ketoacids and dicarbonyls at Hokkaido University using the methods of Kawamura and Ikushima (1993) and Kawamura and Yasui (2005). Briefly, one quarter of the filter was 
extracted with pure water $(10 \mathrm{ml} \times 3)$, which was made by oxidizing organic impurities of Milli Q water with UV light. The extracts (water soluble organics) were passed through a glass column (Pasteur pipette) packed with a quartz wool to remove particles such as filter debris and then concentrated to ca. $0.1 \mathrm{ml}$ using a rotary evaporator under a vacuum. They were further dried by nitrogen blow down and reacted with $14 \% \mathrm{BF}_{3} / n$-butanol at $100{ }^{\circ} \mathrm{C}$ to derive the carboxyl groups to butyl esters and the aldehyde groups to dibutoxy acetals. The derivatives were extracted with $n$-hexane after adding pure water and then determined with GC equipped with a split/splitless injector and a HP-5 fused silica capillary.

Peak identification was performed by a comparison of GC retention times with those of authentic standards. Identification of the esters was confirmed by mass spectral analysis using a GC/MS system (Thermo Trace MS) and authentic standards (Kawamura, 1993). Recoveries of authentic standards spiked to a pre-combusted quartz fiber filter were $71 \%$ for oxalic acid and better than $80 \%$ for malonic, succinic and adipic acids. Recoveries of glyoxylic acid, pyruvic acid and methylglyoxal were $88 \%, 72 \%$ and $47 \%$, respectively. Spiked experiment of diacid standards to the filter sample (QFF 166) showed higher recoveries of oxalic acid (86\%) and malonic acid (94\%) (Kawamura and Yasui, 2005). Duplicate analyses of filter sample showed that analytical errors are within $15 \%$ for major species. Concentrations of the acids and related compounds reported here are corrected for the procedural blanks, but are not corrected for the recoveries although the recovery of methylglyoxal is rather low.

Aliquots of the aerosol filter samples were analyzed for OC and EC by DRI Model 2001 Thermal/Optical Carbon Analyzer (Atmoslytic Inc., Calabasas, CA) at the Hong Kong Polytechnic University following the Interagency Monitoring of 
PROtected Visual Environments (IMPROVE) thermal/optical reflectance (TOR) protocol (Cao et al. 2003; Chow et al., 2004).

\section{Results and discussion}

\subsection{Molecular compositions of dicarboxylic acids, ketoacids and $\alpha$-dicarbonyls in}

$P M_{2.5}$

A homologous series of $\alpha, \omega$-dicarboxylic acids $\left(\mathrm{C}_{2}-\mathrm{C}_{12}\right)$ were first determined in the $\mathrm{PM}_{2.5}$ urban roadside samples of Hong Kong. Their concentrations together with other compounds detected were summarized in Table 1. Other than primary vehicle exhaust, secondary formation is one of the major sources of diacids at this sampling site. Oxalic $\left(\mathrm{C}_{2}\right)$ acid was found as the most abundant diacid, followed by malonic $\left(\mathrm{C}_{3}\right)$ or phthalic $(\mathrm{Ph})$ acid. The fourth most abundant diacid was succinic $\left(\mathrm{C}_{4}\right)$ acid. The predominance of the oxalic $\left(\mathrm{C}_{2}\right)$ acid has been reported for the aerosol and rainwater samples from the urban (Kawamura and Kaplan, 1987; Kawamura and Ikushima, 1993; Khwaja, 1995; Wang et al., 2002, Warneck, P., 2003; Yao et al., 2004; Li and $\mathrm{Yu}, 2005$ ) and remote marine regions (Sempéré and Kawamura, 1996; Kawamura and Sakaguchi, 1999; Kerminen et al., 2000; Mochida et al., 2003a) as well as the arctic atmosphere (Kawamura et al., 1996a; Kerminen et al., 1999). It is important to note that phthalic acid (aromatic acid) is often the second most abundant diacid in the urban roadside $\mathrm{PM}_{2.5}$ samples, especially in summer. This aromatic acid is directly emitted from combustion sources (Kawamura and Kaplan, 1987; Koebel and Elsener, 1998) and/or has been considered to generate in the atmosphere by atmospheric degradation of aromatic hydrocarbons such as naphthalene (Kawamura and Ikushima, 1993). Abundance of the individual species decreased with an increase in carbon chain length, although adipic $\left(\mathrm{C}_{6}\right)$ and azelaic $\left(\mathrm{C}_{9}\right)$ acids are relatively abundant. $\mathrm{C}_{9}$ diacid is an oxidation product of biogenic unsaturated fatty acids 
containing double bond at the $\mathrm{C}_{9}$-position $(\mathrm{OH}$ oxidation should be involved in the production of C9 diacid) (Yokouchi and Ambe, 1986; Kawamura and Gagosian, 1987; Stephanou and Stratigakis, 1993).

Total concentrations of diacids ranged from $224 \mathrm{ng} \mathrm{m}^{-3}$ to $1381 \mathrm{ng} \mathrm{m}^{-3}$ with an average of $692 \mathrm{ng} \mathrm{m}^{-3}$. The most abundant diacid was oxalic acid $\left(\mathrm{C}_{2}\right)$ throughout the seasons, whose concentration range from $64 \mathrm{ng} \mathrm{m}^{-3}$ to $767 \mathrm{ng} \mathrm{m}^{-3}$ with an average of $373 \mathrm{ng} \mathrm{m}^{-3}$. Its relative abundance in the total diacid $\left(\mathrm{C}_{2}-\mathrm{C}_{12}\right)$ fluctuated from $28 \%$ to $66 \%$ (average $49 \%$ ). The second most abundant diacid, on an average basis, was found as phthalic acid (40-105 $\mathrm{ng} \mathrm{m}^{-3}$, average $\left.84 \mathrm{ng} \mathrm{m}^{-3}\right)$, which account for $6-32 \%$ (average $16 \%$ ) of the total diacid concentrations. However, phthalic acid was less

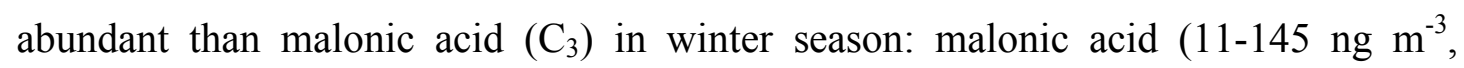
average $68 \mathrm{ng} \mathrm{m}^{-3}$ ) comprised 5-13\% (average 9\%) of the total diacid concentrations. The longer-chain diacids $\left(\mathrm{C}_{5}-\mathrm{C}_{12}\right)$ were less abundant than $\mathrm{C}_{2}-\mathrm{C}_{4}$ species, except adipic $\left(\mathrm{C}_{6}\right)$ and azelaic $\left(\mathrm{C}_{9}\right)$ acids that account for 1-9\% (average $2 \%$ ) and 1-4 \% (average $2 \%$ ) of the total diacids, respectively. Ketocarboxylic acids (10-89 $\mathrm{ng} \mathrm{m}^{-3}$, average: $\left.39 \mathrm{ng} \mathrm{m}^{-3}\right)$ and $\alpha$-dicarbonyls $\left(0.0-21 \mathrm{ng} \mathrm{m}^{-3}\right.$, average: $\left.11 \mathrm{ng} \mathrm{m}^{-3}\right)$ were also detected in the $\mathrm{PM}_{2.5}$ samples. Glyoxylic acid $\left(\omega \mathrm{C}_{2}\right)$ is the dominant oxocarboxylic acids followed by 4-oxobutanoic acid $\left(\omega \mathrm{C}_{4}\right)$ in the urban roadside atmosphere. Their concentrations are slightly lower than those found in Tokyo (Kawamura and Yasui, 2005).

\subsection{Seasonal variations of dicarboxylic acids, ketoacids and $\alpha$-dicarbonyls in $P M_{2.5}$}

The variations of dicarboxylic acids, ketocarboxylic acids and $\alpha$-dicarbonyls detected in $\mathrm{PM}_{2.5}$ during winter (January and November, 2003) and summer (June, 2003) were shown in Table 1. Generally, their concentrations were higher in winter 
than in summer. Although the concentrations of most species were higher in winter, concentrations of $\mathrm{C}_{6}, \mathrm{C}_{8}, \mathrm{C}_{11}, \mathrm{C}_{12}, \mathrm{~F}, \mathrm{mM}, \mathrm{Ph}$, MeGly were found to be higher in summer. But, the concentrations of total dicarboxylic acids, ketocarboxylic acids and $\alpha$-dicarbonyls collected in sunny days during summer are slightly higher or similar to the concentrations collected in winter. The lower mixing heights, the formation of the inversion layers, and the less chance of wet deposition can contribute to the accumulation of air pollutants in the winter in Hong Kong (Yao et al., 2004). The total dicarboxylic acids, ketocarboxylic acids and $\alpha$-dicarbonyls collected during sunny days in summer were 987,47 and $15 \mathrm{ng} \mathrm{m}^{-3}$, respectively while in rainy days the concentrations declined significantly to 335,15 and $10 \mathrm{ng} \mathrm{m}^{-3}$, respectively. Moreover, low concentrations of diacids in summer can be explained by dilution of polluted air by the inflow of marine air mass (in summer marine air masses are transported from South China Sea; in winter continental air masses are transported from Pear River Delta Region).

The relative abundances of the detected species were also different in winter and summer. On the average, in winter, oxalic acid was the most abundant species, followed by malonic acid and then phthalic acid, with oxalic acid being over five times as abundant as malonic acid. In contrast, in summer, although oxalic acid was still the most abundant species, it was only slightly more than the twice of the second most abundant species, phthalic acid. It is likely that phthalic acid was produced more favorably than malonic and succinic acid in summer, as described later.

When concentrations of total dicarboxylic acids, ketocarboxylic acids and dicarbonyls are divided by the total aerosol mass, seasonal variations of these ratios were obtained (Table 2). Abundances of total dicarboxylic acids relative to the aerosol mass were higher (winter: $1.16 \%$; summer: $1.21 \%$ ) than those of other urban areas 
(Nanjing, 0.4-1.4 \%; Tokyo, $0.46 \%$ ) (Wang et al., 2002; Kawamura and Ikushima, 1993), although the seasonal variations were not significant in Hong Kong. Table 2 presents the seasonal variations of the total amounts of diacid carbon, ketoacid carbon and dicarbonyl carbon divided by organic carbon (OC). The total diacids accounted for $1.12 \%$ to $2.47 \%$ of OC (winter average: $1.68 \%$; summer average: $1.94 \%$ ), indicating that they are the compound group with the highest fraction in OC. Phthalic acid carbon relative to $\mathrm{OC}$ fluctuated from 0.15 to $0.81 \%$ (average $0.43 \%$ ) with a summer maximum, indicating that the atmospheric production of this aromatic diacid is enhanced in the summer. Adipic, suberic, sebacic, methylmaleic, fumaric acids and methylglyoxal also showed a higher percentage in summer than in winter. During sunny days in summer, all major species (oxalic, malonic, succinic, phthalic, and glyoxylic acids, etc.) have higher relative abundance in aerosol mass and OC. These species showed a summer maximum, indicating an enhanced secondary production from aromatic hydrocarbons such as benzene and toluene, cyclic olefins and unsaturated fatty acids (Kawamura and Ikushima, 1993) under a strong solar radiation (winter: $12.3 \mathrm{MJ} \mathrm{m}^{-2}$; sunny day summer: $22.1 \mathrm{MJ} \mathrm{m}^{-2}$; rainy day summer: $9.4 \mathrm{MJ} \mathrm{m}^{-}$ 2).

\subsection{Comparison with literature data}

Due to the limited data on dicarboxylic acids in $\mathrm{PM}_{2.5}$ in the literature, concentrations of dicarboxylic acids in $\mathrm{TSP} / \mathrm{PM}_{10} / \mathrm{PM}_{2.5}$ were used for comparison. The data listed in Table 3 include a literature overview of the selected compounds, determined at other sites with different analytical methods. In general, the reported urban concentrations are higher than those at the remote or marine sites (except for winter time in Hok Tsui). Similar chain length distributions of dicarboxylic acids, 
with a predominance of oxalic acid, have been reported in all the sites (Table 3). There are some differences between the relative abundances of the diacids found in this study and those in most other regions in the world where oxalic, malonic and succinic acids were often the three most abundant species (see Table 3 ). The mean concentration of oxalic acid is slightly higher or comparable to those reported in other urban areas like, Christchurch, Leipzig, Tokyo and Vienna but is lower than the samples reported in the urban atmosphere from Chinese megacities, like Shanghai and Nanjing. Similar to oxalic acid, the mean concentrations of malonic, succinic, adipic and azelaic acids in this study were higher than those in Christchurch, Leipzig and Tokyo, but significantly lower than in Vienna and some Chinese cities.

Interestingly, phthalic acid in the Hong Kong aerosols is as abundant as malonic acid or even higher in summer. Further, high concentrations of methylmaleic acid were also observed in the aerosols. These unsaturated diacids are probably derived from incomplete combustion of aromatic hydrocarbons (benzene, toluene and naphthalenes etc.) in vehicular exhaust (Kawamura and Kaplan, 1987). Alternatively, these unsaturated diacids can be produced by atmospheric oxidation of aromatic hydrocarbons (Kawamura and Ikushima, 1993; Kawamura and Yasui, 2005). In fact, high concentrations of toluene (winter: $34 \mu \mathrm{g} \mathrm{m} \mathrm{m}^{-3}$; summer: $41 \mu \mathrm{g} \mathrm{m} \mathrm{m}^{-3}$ ) and naphthalenes (winter: $1.2 \mu \mathrm{g} \mathrm{m}^{-3}$; summer: $1.9 \mu \mathrm{g} \mathrm{m}^{-3}$ ) (much higher than previously reported data from other cities, Fang et al., 2004; Park et al., 2002) observed at this roadside sampling location (samples were collected at 2004) were one of the possible sources for the high concentration of methylmaleic and phthalic acids detected. Although atmospheric degradation of volatile organic compounds including aromatic hydrocarbons and its mechanisms were extensively discussed (e.g., Atkinson, R. and 
Arey, J., 2003), formation mechanisms of diacids including unsaturated diacids have been poorly understood.

\subsection{Relationship between Dicarboxylic Acids and Ozone}

Interestingly, good correlation was observed between total dicarboxylic acids and ozone (especially in summer season, $r=0.94$ ) over the roadside sampling site. Figure 1 plots total dicarboxylic acid concentrations as a function of ozone (24 hours average collected at background site, Tap Mun (about $25 \mathrm{~km}$ away from the roadside sampling location). The present results seem to be consistent with the previous studies from Tokyo (Kawamura and Ikushima, 1993; Kawamura and Yasui, 2005).

Although the total dicarboxylic acids increased with an increase in atmospheric ozone concentrations (Figure 1), a degree of the increase was found to depend on a carbon chain length and structure of diacid species. Better correlations were obtained between the smaller diacids $\left(\mathrm{C}_{2}-\mathrm{C}_{4}\right)$ and ozone as well as solar radiation (when the samples collected in rainy days were removed). Oxalic acid presents the best relationship with ozone $(\mathrm{r}=0.86)$, followed by malonic $(\mathrm{r}=0.64)$, and succinic $(r=0.56)$ acids. Further, the ratio of malonic acid-C/OC presents the best relationship with solar radiation $(\mathrm{r}=0.97)$, follow by succinic acid-C/OC ratio $(\mathrm{r}=$ 0.77 ), and oxalic acid-C/OC ratio $(r=0.72)$ (Figure 2$)$. These results suggested that origins of LMW diacids seem to be related to secondary photochemical processes in the atmosphere rather than primary emissions from vehicular exhaust. Longer chain dicarboxylic acids gave lower correlation coefficients. However, some species present negative slope but with fair correlation coefficients. Moreover, ratios of total ketocarboxylic acids/OC (\%) and total dicarbonyls/OC increased as a function of ozone $(r=0.60$ and $r=0.44)$ and solar radiation $(r=0.90$ and $r=0.55)$, respectively. 
The LMW ketocarboxylic and dicarbonyls may further be oxidized in the atmosphere to result in small diacids.

3.5 Correlations of selected diacids, ketoacids and dicarbonyls and the ratios of $C_{3} / C_{4}, C_{6} / C_{9}$ and $P h / C_{9}$

Table 4 shows the correlation coefficients of selected diacids, ketoacids and dicarbonyls. Strong correlations were observed among $C_{2}, C_{3}, C_{4}, C_{9}, \omega C_{2}$ and $\omega C_{9}(r$ $>0.78)$, especially in summer $(\mathrm{r}>0.88)$. Other than direct vehicular emission, photochemical processes largely control the atmospheric concentrations of these species. Moreover, the ketoacids, $\omega \mathrm{C}_{2}$ and $\omega \mathrm{C}_{9}$ may be further oxidized to $\mathrm{C}_{2}$ and $\mathrm{C}_{9}$ diacids, respectively since good correlations were found between $\omega C_{2}$ and $C_{2}(r=$ $0.81)$ as well as $\omega C_{9}$ and $C_{9}(r=0.88)$. Further, $\omega C_{2}$ is well correlated with Gly $(r=$ 0.74). This is consistent with the atmospheric oxidation process proposed for Gly to $\omega \mathrm{C}_{2}$ (Kawamura et al., 1996a). $\mathrm{C}_{3}, \mathrm{C}_{4}$ diacids may further be oxidized to $\mathrm{C}_{2}$ via the breakdown of intermediates such as ketomalonic acid $\left(\mathrm{kC}_{3}\right)($ Kawamura and Ikushima, 1993), so that strong correlations were observed between $\mathrm{C}_{3}, \mathrm{C}_{4}$ and $\mathrm{kC}_{3}$ (Table 4).

In previous study, $\mathrm{C}_{3} / \mathrm{C}_{4}$ ratio was used as indicators of enhanced photochemical production of dicarboxylic acids in the atmosphere (Kawamura and Ikushima, 1993; Kawamura and Sakaguchi, 1999; Yao et al., 2004). Malonic acid (C C $\left._{3}\right)$ is derived from the incomplete combustion of fossil fuels or from the secondary atmospheric production. Lower $\mathrm{C}_{3} / \mathrm{C}_{4}$ ratio $(0.25-0.44$, average 0.35$)$ were observed in vehicular exhaust than those in atmospheric aerosol (0.56-2.9, average 1.6) because malonic acid is thermally less stable than succinic acid, the degradation of malonic acid in the combustion process is probably more significant than its production (Kawamura and Ikushima, 1993). As shown in Table 5, the winter samples (1.04-1.68, average 1.29) have lower $C_{3} / C_{4}$ ratios than the summer samples (non-rainy days) 
(1.29-2.21, average 1.86). The higher concentrations of $\mathrm{C}_{3}$ over $\mathrm{C}_{4}$ suggest that malonic acid is in part produced secondarily in the atmosphere by photo-induced reactions. However, the ratios were much smaller than 3, which is used as an index for secondary formation of dicarboxylic acids (Kawamura and Sakaguchi, 1999; Yao et al., 2004). Therefore, vehicle exhaust was also important sources of diacids in both seasons especially near the roadside with a tunnel. Nevertheless, the higher averaged $\mathrm{C}_{3} / \mathrm{C}_{4}$ ratio in summer suggested a larger contribution of secondary sources to particulate dicarboxylic acids. Similar seasonal changes in $\mathrm{C}_{3} / \mathrm{C}_{4}$ ratios have been reported in the urban atmosphere (Kawamura and Ikushima, 1993; Yao et al., 2004).

As $\mathrm{C}_{6}$ and phthalic $(\mathrm{Ph})$ acids are produced by the atmospheric oxidation of anthropogenic cyclic hexene and aromatic hydrocarbons such as naphthalene, respectively (Kawamura and Ikushima, 1993) whereas $C_{9}$ is from biogenic unsaturated fatty acids (Kawamura and Ikushima, 1993), we assume that $\mathrm{C}_{6} / \mathrm{C}_{9}$ and $\mathrm{Ph} / \mathrm{C}_{9}$ ratios may be used as a potential indicator of source strength of anthropogenic and biogenic precursors to the aerosol diacids. In the Hong Kong roadside aerosols, $\mathrm{C}_{6} / \mathrm{C}_{9}(0.43-0.78$, average 0.91$)$ and $\mathrm{Ph} / \mathrm{C}_{9}$ ratios $(3.33-10.90$, average 6.12) were higher than those in Tokyo $\left(\mathrm{C}_{6} / \mathrm{C}_{9}=0.72 ; \mathrm{Ph} / \mathrm{C}_{9}=0.83\right)$ but lower than those in Los Angeles in early $1980 \mathrm{~s}\left(\mathrm{C}_{6} / \mathrm{C}_{9}=7.4 ; \mathrm{Ph} / \mathrm{C}_{9}=8.0\right)$. These results suggest that the relative contribution of anthropogenic to biogenic inputs in Hong Kong and Tokyo is much less significant than in Los Angeles. These results suggest that secondary formation of dicarboxylic acids in $\mathrm{PM}_{2.5}$ was generally more important in the summer, although primary exhaust emission was also one of the dominant sources.

\section{Summary and Conclusions}


Molecular distributions and seasonal changes of water soluble organic compounds including dicarboxylic acids, ketocarboxylic acids and dicarbonyls were determined in the Hong Kong roadside atmosphere during winter and summer 2003. Oxalic $\left(\mathrm{C}_{2}\right)$ acid was found as the most abundant diacid, followed by malonic $\left(\mathrm{C}_{3}\right)$ or phthalic $(\mathrm{Ph})$ acid. The concentrations of the total diacids, total ketoacids and total dicarbonyls were ranged from 224 to $1381 \mathrm{ng} \mathrm{m}^{-3}, 10$ to $89 \mathrm{ng} \mathrm{m}^{-3}$ and 5 to $21 \mathrm{ng} \mathrm{m}^{-3}$ respectively. Their abundances in $\mathrm{PM}_{2.5}$ mass concentrations were $1.18 \%, 0.06 \%$ and $0.02 \%$, respectively. However, their seasonal variations were not significant. Generally, the higher concentrations observed in winter is due to the heavy rainfall during summer period that wash out most of the water-soluble diacid in the atmosphere (rainfall: $21.7 \mathrm{~mm}$ in January, $523.5 \mathrm{~mm}$ in June and $50.1 \mathrm{~mm}$ in November). Moreover, lower concentrations of diacids in summer can be explained by dilution of polluted air by the inflow of marine air mass although photochemical production of the diacids should be more important in summer than winter.

The high abundance of total diacid carbons in OC (winter average: $1.68 \%$; summer average: $1.94 \%$ ) indicate that diacids are one of the major organic compound classes in the roadside environment. Relatively high concentrations of phthalic and methylmaleic acids were observed (especially in summer), which were explained by the atmospheric oxidation of toluene (winter: $33.8 \mu \mathrm{g} \mathrm{m}^{-3}$; summer: $41.3 \mu \mathrm{g} \mathrm{m}^{-3}$ ) and naphthalenes (winter: $1.2 \mu \mathrm{g} \mathrm{m}^{-3}$; summer: $1.9 \mu \mathrm{g} \mathrm{m}^{-3}$ ) at this sampling location. Good correlations were observed between small diacid carbon/OC (\%) and ozone as well as solar radiation, suggesting that dicarboxylic acids are largely produced in the atmosphere by secondary photochemical reactions.

The ratios of $\mathrm{C}_{3}$ to $\mathrm{C}_{4}$ and $\mathrm{C}_{6}$ to $\mathrm{C}_{9}$ were used to distinguish the primary and secondary sources as well as source strength of anthropogenic and biogenic 
precursors in the atmosphere, respectively. $\mathrm{C}_{3} / \mathrm{C}_{4}$ ratios were within the values reported for direct vehicular emissions and secondary organic aerosol formation. The $\mathrm{C}_{6} / \mathrm{C}_{9}$ ratios suggested that the contribution of anthropogenic inputs in Hong Kong and Tokyo is much less significant than in Los Angeles in early 1980s. This study suggested that in addition to primary vehicular exhaust, secondary formation of particulate diacids by photo-oxidation reaction is also important in the roadside atmosphere. High concentrations of aromatic precursors (toluene and naphthalenes) in Hong Kong may serve as important source for the high abundance of unsaturated diacids (methylmaleic and phthalic acids) detected in the Hong Kong aerosols.

\section{Acknowledgements}

This project is supported by the Research Grants Council of Hong Kong (PolyU5145/03E) and the Natural Science Foundation of China (NSFC 40205018, 40121303) and by the Japanese Ministry of Education, Science and Culture through Grant-in Aid No. 17340166.

\section{References}

Atkinson, R. and Arey, J., 2003. Atmospheric degradation of volatile organic compounds. Chemical Reviews 103, 4605-4638.

Cao, J. J., Lee, S. C., Ho, K. F., Zhang, X. Y., Zou, S. C., Fung, K., Chow, J. C., Watson, J. G., 2003. Characteristics of carbonaceous aerosol in Pearl River Delta Region, China during 2001 winter period. Atmospheric Environment 37, 1451-1460.

Chow, J. C., J. G. Watson, L. W. Chen, et al. Equivalence of elemental carbon by thermal/optical reflectance and transmittance with different temperature protocols, Environ. Sci. Technol., 38(16), 4414- 4422, 2004.

Cruz, C. and Pandis, S.N., 1998. The effect of organic coatings on the cloud condensation nuclei activation of inorganic atmospheric aerosol. Journal of Geophysical Research 103, 111-123. 
Environmental Protection Department, 2002. Hong Kong Special Administrative Region Government. Report Ro355.01, pp. 1-10 (Chapter 3).

Falkovich, A. H., Graber, E. R., Schkolnik, G., Rudich, Y., Maenhaut, W., Artaxo, P., 2005. Low molecular weight organic acids in aerosol particles from Rondonia, Brazil, during the biomass-burning, transition and wet periods. Atmospheric Chemistry and Physics 5, 781-797.

Fang, G.-C., Wu, Y.-S., Chen, M.-H., Ho, T.-T., Huang, S.-H., Rau, J.-Y., 2004. Polycyclic aromatic hydrocarbons study in Taichung, Taiwan, during 2002-2003. Atmospheric Environment 38, 3385-3391.

Fraser, M.P., Yue, Z.W., Tropp, R.J., Kohl, S.D., Chow, J.C., 2002. Molecular composition of organic fine particulate matter in Houston, TX. Atmospheric Environment 36, 5751-5758.

Grosjean, D., Cauwenberghe, K.V., Schmid, J.P., Kelley, P.E., Pitts Jr., J.N., 1978. Identification of $\mathrm{C} 3-\mathrm{C} 10$ aliphatic dicarboxylic acids in airborne particulate matter. Environmental Science and Technology 12, 313-317.

Hatakeyama, S., Ohno, M., Weng, J., Takagi, H., Akimoto, H., 1987. Mechanism for the formation of gaseous and particulate products from ozone-cycloalkene reactions in air. Environmental Science and Technology 21, 52-57.

Huang, X.-F., Hu, M., He L.-Y., Tang, X.-Y., 2005. Chemical characterization of water-soluble organic acids in $\mathrm{PM}_{2.5}$ in Beijing, China. Atmospheric Environment 39, 2819-2827.

Jacobson, M.C., Hanson, H.C., Noone, K.J., Charlson, R.J., 2000. Organic atmospheric aerosols: review and state of the science. Reviews of Geophysics 38, 267-294.

Kawamura, K. and Ikushima, K., 1993. Seasonal changes in the distribution of dicarboxylic acids in the urban atmosphere. Environmental Science and Technology 27, 2227-2235.

Kawamura, K. and Kaplan, I.R., 1987. Motor exhaust emissions as a primary source for dicarboxylic acids in Los Angeles ambient air. Environmental Science and Technology 21, 105-110.

Kawamura, K. and Gagosian R. B., 1987. Implication of $\omega$-oxocarboxylic acids in the remote marine atmosphere for photo-oxidation of unsaturated fatty acids. Nature 325, 330-332.

Kawamura, K. and Usukura, K., 1993. Distribution of low molecular weight dicarboxylic acids in the north pacific aerosol samples. Journal of Oceanography 49, 271-283. 
Kawamura, K., Kasukabe, H., Barrie, L.A., 1996a. Source and reaction pathways of dicarboxylic acids, ketoacids and dicarbonyls in Arctic aerosols: one year of observations.

Atmospheric Environment 30, 1709-1722.

Kawamura, K., Sempéré, R., Imai, Y., 1996b. Water soluble dicarboxylic acids and related compounds in Antarctic aerosols. Journal of Geophysical Research 101, 18721-18728.

Kawamura, K., Steinberg, S., Kaplan, I.R., 1996c. Concentrations of monocarboxylic and dicarboxylic acids and aldehydes in Southern California wet precipitations: comparison of urban and non-urban samples and compositional changes during scavenging. Atmospheric Environment 30, 1035-1052.

Kawamura, K., Sakaguchi, F., 1999. Molecular distribution of water soluble dicarboxylic acids in marine aerosols over the Pacific Ocean including tropics. Journal of Geophysical Research 104, 3501-3509.

Kawamura, K. and Yasui, O., 2005. Diurnal changes in the distribution of dicarboxylic acids, ketocarboxylic acids and dicarbonyls in the urban Tokyo atmosphere. Atmospheric Environment 39, 1945-1960.

Kerminen, V. M., Teinila, K., Hillamo, R., Makela, T., 1999. Size-segregated chemistry of particulate dicarboxylic acids in the Arctic atmosphere. Atmospheric Environment 33, 2089-2100.

Kerminen, V.-M., Ojanen, C., Pakkanen, T., Hillamo, R., Aurela, M., Merilainen, J., 2000. Low-molecular-weight dicarboxylic acids in an urban and rural atmosphere. Journal of Aerosol Science 31, 349-362.

Khwaja, H.A., 1995. Atmospheric concentrations ofcarboxylic acids and related compounds at a semiurban site. Atmospheric Environment 29, 127-139.

Koebel, M and Elsener, M., 1998. Oxidation of diesel-generated volatile organic compounds in the selective catalytic reduction process. Industrial and Engineering Chemistry Research 37, 3864-3868.

Lightstone, J. M., Onasch, T. B., Imre, D., 2000. Deliquescence, efflorescence, and water activity in ammonium nitrate and mixed ammonium nitrate/succinic acid microparticles. Journal of Physical Chemistry A 104, 9337-9346.

Limbeck, A., Puxbaum, H., 1999. Organic acids in continental background aerosols. Atmospheric Environment 33, 1847-1852.

Limbeck, A., Puxbaum, H., Otter, L., Scholes, M.C., 2001. Semivolatile behavior of dicarboxylic acids and other polar organic species at a rural background site (Nylsvley, RSA). Atmospheric Environment 35, 1853-1862. 
Meszaros, E., Barcza, T., Gelencser, A., Hlavay, J., Kiss, G., Krivacsy, Z., Molnar, A., Polyak, K., 1997. Size distributions of inorganic and organic species in the atmospheric aerosol in Hungary. Journal of Aerosol Science 28, 1163-1175.

Mochida, M., Kawabata, A., Kawamura, K., Hatsushika, H., Yamazaki, K., 2003. Seasonal variation and origins of dicarboxylic acids in the marine atmosphere over the western North Pacific, Journal of Geophysical Research 108 (D6), 4193, doi:10.1029/2002JD002355

Park, S. S., Kim, Y. J., Kang, C. H., 2002. Atmospheric polycyclic aromatic hydrocarbons in Seoul, Korea. Atmospheric Environment 36, 2917-2924.

Ricard, V., Jaffrezo, J.-L., Kerminen, V.-M., Hillamo, R. E., Sillanpaa, M., Ruellan, S., Liousse, C., Cachier, H., 2002. Two years of continuous aerosol measurements in northern Finland. Journal of Geophysical Research 107 (D11), 4129, 10.1029/2001JD000952

Rohrl, A. and Lammel, G., 2001. Low-molecular weight dicarboxylic acids and glyoxylic acid: seasonal and air mass characteristics. Environmental Science and Technology 35, 95-101.

Rogge, W.F., Mazurek, M.A., Hildemann, L.M., Cass, G.R., Simoneit, B.R.T., 1993. Quantification of urban organic aerosols at a molecular level: identification, abundance and seasonal variation. Atmospheric Environment 27A, 1309-1330.

Sempéré, R., Kawamura, K., 1996. Low molecular weight dicarboxylic acids and related polar compounds in the remote marine rain sample collected from Western Pacific. Atmospheric Environment 30, 1609-1619.

Shulman, M.L., Jacobson, M.C., Charlson, R.J., Synovec, R.E., Young, T.E., 1996. Dissolution behavior and surface tension effects of organic compounds in nucleating cloud droplets. Geophysical Research Letters 23, 277-280.

Stephanou, E. G. and Stratigakis, N., 1993. Oxocarboxylic and alpha., omega.dicarboxylic acids: photooxidation products of biogenic unsaturated fatty acids present in urban aerosols. Environmental Science and Technology 27, 1403-1407

Wang, G., Niu, S., Liu, C., Wang, L., 2002. Identification of dicarboxylic acids and aldehydes of $\mathrm{PM}_{10}$ and $\mathrm{PM}_{2.5}$ aerosols in Nanjing, China. Atmospheric Environment 36, 1941-1950.

Wang, H. and Shooter, D., 2004. Low molecular weight dicarboxylic acids in PM10 in a city with intensive solid fuel burning. Chemosphere 56, 725-733.

Warneck, P., 2003. In-cloud chemistry opens pathway to the formation of oxalic acid in the marine atmosphere. Atmospheric Environment 37, 2423-2427

Yao, X. H., Fang, M., Chan, C. K., 2002. Size distributions and formation of dicarboxylic acids in atmospheric particles. Atmospheric Environment 36, 2099-2107. 
Yao, X., Fang, M., Chan, C.K., Ho, K.F., Lee, S.C., 2004. Characterization of dicarboxylic acids in $\mathrm{PM}_{2.5}$ in Hong Kong. Atmospheric Environment 38, 963-970.

Yokouchi, Y. and Ambe, Y., 1986. Characterization of polar organics in airborne particulate matter. Atmospheric Environment 20, 1727-1734.

Li, Y. C. and Yu, J. Z., 2005. Simultaneous determination of momo- and dicarboxylic acids, $\omega$-oxo-carboxylic acids, midchain ketocarboxylic acids and aldehydes in atmospheric aerosol samples. Environmental Science and Technology 39, 7616-7624. Yue, Z., Fraser, M. P., 2004. Polar organic compounds measured in fine particulate matter during TexAQS 2000. Atmospheric Environment 38, 3253-3261. 
Table 1. Concentrations of low molecular weight dicarboxylic acids, ketocarboxylic acids and $\alpha$-dicarbonyls in $\mathrm{PM}_{2.5}$ samples (total, winter and summer) from urban roadside of Hong Kong

\begin{tabular}{|c|c|c|c|c|c|c|c|}
\hline \multirow[t]{2}{*}{ Compounds } & \multicolumn{3}{|c|}{$\begin{array}{c}\text { Concentrations }\left(\mathrm{ng} \mathrm{m}^{-3}\right) \\
n=14\end{array}$} & \multicolumn{2}{|c|}{$\begin{array}{c}\text { Winter }\left(\mathrm{ng} \mathrm{m}^{-3}\right) \\
\mathrm{n}=7\end{array}$} & \multicolumn{2}{|c|}{$\begin{array}{c}\text { Summer }\left(\mathrm{ng} \mathrm{m}^{-3}\right) \\
n=7\end{array}$} \\
\hline & Range & Average & S.D. & Average & S.D. & Average & S.D. \\
\hline \multicolumn{8}{|l|}{ Dicarboxylic acids } \\
\hline Oxalic, C2 & $63.8-767$ & 373 & 247 & 478 & 207 & 268 & 251 \\
\hline Malonic, C3 & $10.5-145$ & 68.4 & 41.6 & 89.1 & 30.4 & 47.6 & 42.7 \\
\hline Succinic, C4 & $13.1-121$ & 52.5 & 31.8 & 71.88 & 28.29 & 33.0 & 22.7 \\
\hline Glutaric, C5 & $2.82-28.1$ & 13.50 & 8.17 & 20.0 & 5.46 & 6.95 & 3.85 \\
\hline Adipic, C6 & $3.78-32.1$ & 11.7 & 7.53 & 10.7 & 6.25 & 12.7 & 9.03 \\
\hline Pimeric, C7 & $0.74-9.69$ & 2.30 & 2.33 & 3.20 & 3.00 & 1.40 & 0.93 \\
\hline Suberic, C8 & $0.00-6.67$ & 2.25 & 1.88 & 1.93 & 2.70 & 2.56 & 0.41 \\
\hline Azelaic, C9 & $6.01-28.1$ & 12.9 & 6.74 & 16.8 & 7.27 & 9.06 & 3.24 \\
\hline Sebacic, C10 & $0.00-3.97$ & 1.49 & 1.30 & 1.52 & 1.43 & 1.47 & 1.27 \\
\hline Undecanedioic, C11 & $0.94-4.61$ & 2.60 & 1.18 & 1.94 & 0.98 & 3.27 & 1.01 \\
\hline Dodecanedioic, C12 & $0.00-3.97$ & 0.26 & 0.98 & 0.00 & 0.00 & 0.53 & 1.39 \\
\hline Methylmalonic, iC4 & $1.24-7.91$ & 3.20 & 1.98 & 4.73 & 1.69 & 1.66 & 0.42 \\
\hline Methylsuccinic, iC5 & $1.98-15.3$ & 7.17 & 4.55 & 11.0 & 2.85 & 3.35 & 1.64 \\
\hline 2-Methylglutaric, iC6 & $0.62-3.00$ & 1.43 & 0.68 & 1.82 & 0.58 & 1.05 & 0.55 \\
\hline Maleic, M & $2.21-37.2$ & 16.2 & 10.6 & 19.9 & 13.5 & 12.4 & 5.18 \\
\hline Fumaric, F & $0.29-8.66$ & 3.26 & 2.54 & 3.15 & 2.35 & 3.38 & 2.91 \\
\hline Methylmaleic, mM & $1.15-14.3$ & 6.46 & 3.83 & 6.36 & 3.93 & 6.57 & 4.04 \\
\hline Phthalic, Ph & $40.1-105$ & 83.9 & 21.3 & 78.0 & 24.9 & 89.9 & 16.7 \\
\hline Isophthalic, iPh & $2.00-63.0$ & 14.1 & 19.9 & 15.3 & 21.4 & 12.9 & 19.9 \\
\hline Malic, hC4 & $1.15-10.1$ & 4.53 & 2.68 & 6.54 & 2.11 & 2.51 & 1.28 \\
\hline Ketomalonic, kC3 & $0.00-15.7$ & 6.66 & 5.06 & 10.4 & 3.85 & 2.89 & 2.73 \\
\hline 4-Ketopimelic, $\mathrm{kC7}$ & $0.00-14.0$ & 4.08 & 3.65 & 5.32 & 4.07 & 2.84 & 2.95 \\
\hline Total diacids & $224-1381$ & 692 & 357 & 858 & 306 & 526 & 344 \\
\hline \multicolumn{8}{|l|}{ Ketocarboxylic acids } \\
\hline Pyruvic & $0.00-8.20$ & 2.36 & 2.62 & 3.66 & 2.71 & 1.06 & 1.90 \\
\hline Glyoxylic, $\omega \mathrm{C} 2$ & $2.49-74.4$ & 30.9 & 21.8 & 43.2 & 18.6 & 18.5 & 18.2 \\
\hline 3-Oxopropanoic, $\omega \mathrm{C} 3$ & $0.28-1.19$ & 0.66 & 0.31 & 0.72 & 0.34 & 0.61 & 0.28 \\
\hline 4-Oxobutanoic, $\omega \mathrm{C} 4$ & $0.00-7.49$ & 3.01 & 2.71 & 3.30 & 2.72 & 2.73 & 2.89 \\
\hline 9-Oxononaoic, $\omega \mathrm{C} 9$ & $0.00-6.15$ & 2.59 & 1.70 & 3.47 & 1.38 & 1.70 & 1.58 \\
\hline Total ketoacids & $9.85-89.2$ & 39.5 & 24.6 & 50.7 & 18.2 & 23.6 & 17.6 \\
\hline \multicolumn{8}{|l|}{$\alpha$-Dicarbonyls } \\
\hline Glyoxal, Gly & $0.00-7.61$ & 2.73 & 2.94 & 5.26 & 1.93 & 0.19 & 0.25 \\
\hline Methylglyoxal, MeGly & $0.00-16.6$ & 8.22 & 5.24 & 6.40 & 3.81 & 10.0 & 6.10 \\
\hline Total dicarbonyls & $0.00-21.0$ & 10.9 & 5.62 & 11.66 & 5.23 & 10.2 & 6.31 \\
\hline $\mathrm{OC}\left(\mu \mathrm{g} \mathrm{m}^{-3}\right)$ & $6.98-21.3$ & 13.1 & 4.72 & 16.2 & 3.33 & 10.1 & 3.97 \\
\hline $\mathrm{EC}\left(\mu \mathrm{g} \mathrm{m}^{-3}\right)$ & $4.90-20.1$ & 11.7 & 3.80 & 11.2 & 5.27 & 12.2 & 1.83 \\
\hline
\end{tabular}


Table 2. Seasonal changes of total dicarboxylic acids, total ketocarboxylic acids and total $\alpha$-dicarbonyls in the percentage of $\mathrm{PM}_{2.5}$ mass and relative abundance of carbon in organic carbon $(\mathrm{OC})$

\begin{tabular}{|l|c|c|c|}
\hline \multirow{2}{*}{ Relative abundance } & \multicolumn{3}{|c|}{ Compounds } \\
\cline { 2 - 4 } & Total diacids & Total ketoacids & Total dicarbonyls \\
\hline \% in $\mathrm{PM}_{2.5}$ & 1.16 & 0.070 & 0.018 \\
\hline Winter & 1.21 & 0.058 & 0.030 \\
\hline Summer & 1.68 & 0.110 & 0.035 \\
\hline carbon \% in OC & 1.94 & 0.093 & 0.062 \\
\hline Winter & \multicolumn{3}{|c|}{} \\
\hline Summer &
\end{tabular}

